\title{
Computer-Aided System of Virtual Testing of Gas Turbine Engines
}

\author{
Viktor N. Rybakov, Andrey Y. Tkachenko, Venedikt S. Kuz'michev and Ilia N. Krupenich \\ Samara National Research University, Department of Theory of Aircraft Engines, 34, Moskovskoye Shosse, Samara, 443086, Russia
}

\begin{abstract}
The article describes the concept of a virtual lab that includes subsystem of gas turbine engine simulation, subsystem of experiment planning, subsystem of measurement errors simulation, subsystem of simulator identification and others. The basis for virtual lab development is the computer-aided system of thermogasdynamic research and analysis "ASTRA". The features of gas turbine engine transient modes simulator are described. The principal difference between the simulators of transient and stationary modes of gas turbine engines is that the energy balance of the compressor and turbine becomes not applicable. The computer-aided system of virtual gas turbine engine testing was created using the developed transient modes simulator. This system solves the tasks of operational (throttling, speed, climatic, altitude) characteristics calculation, analysis of transient dynamics and selection of optimal control laws. Besides, the system of virtual gas turbine engine testing is a clear demonstration of gas turbine engine working process and the regularities of engine elements collaboration. The interface of the system of virtual gas turbine engine testing is described in the article and some screenshots of the interface elements are provided. The developed system of virtual gas turbine engine testing provides means for reducing the laboriousness of gas turbine engines testing. Besides, the implementation of this system in the learning process allows the diversification of lab works and therefore improve the quality of training.
\end{abstract}

\section{Introduction}

Modelling is the most popular way of complex systems (technical objects and control systems) examination during the designing, development and analyzing [1].

Simulation modelling is a method of experiment simulation: real-time experimental investigation of a virtual prototype of an engine that is implemented using a simulator instead of an engine itself.

One of the important ways to provide a high efficiency of the engine designing process is to develop a virtual model of its working process, suitable for use during all the stages of engine life cycle. The greater part of information about the engine behavior is obtained during the physical experimental investigations due to the lack of adequacy of modern simulators [2]. Physical experimental investigations of the gas turbine engines are quite time-consuming and expensive, so it is a good policy to combine them with a virtual investigations during the design and development stages.

Computer-aided system of termogasdynamic calculations and analysis of the gas turbine engines (ASTRA) [3], developed at the Samara State Aerospace University [4], [5] may be used as a basis for development of a virtual testing lab. Thermogasdynamic models of the gas turbine engines (GTEs), implemented using the ASTRA are suitable for calculating the performance data, optimizing the control programs of engines and other tasks of conceptual designing.

\section{Computer-aided system of virtual testing of gas turbine engines}

This paper suggests the concept of GTE virtual testing lab [6]-[8]. The principal elements of the lab are: measurement imitation subsystem, design of experiments subsystem, mathematical model identification subsystem, engine simulation subsystem (ASTRA), information subsystem, documentation subsystem and testing visualization subsystem (Fig. 1).

Design of experiments subsystem is intended to draw up a plan of virtual experiment.

Measurement imitation subsystem is intended to introduce deviations from the design values (imitating individual features of a certain engine generated during its production, e.g. manufacturing errors) and random measurement errors. This subsystem is crucial for methods of processing the results of the experiment.

Fig. 2 shows the scheme of deviations and measurement errors simulation.

Mathematical model identification subsystem. During the engine designing process the first-level mathematical models are mostly used. These models are the systems of nonlinear equations that interrelate the engine parameters with the characteristics of its elements $Q$ and the 
external factors $X$ (ambient conditions and the mode of operation) using the joint operation equations:

$$
P=f(Q, X) \text {. }
$$

The essence of the identification process is to redefine the elements' characteristics $Q$ using the measured results of the experimental investigations $P$. It should be mentioned that the number of unknown parameters $A$ is usually much higher than the number of measured parameters $P$.

Documentation subsystem is intended to organize the results of experimental investigations and performance data.

Testing visualization subsystem provides the audio and visual imitation of the testing process (graphical representation of the measured parameters, imitation of the gas flow, noise imitation etc.).
Information subsystem is a collection of databases: of initial data, mathematical models and the testing results (Fig. 3).

The ASTRA CAE-system includes the numerical integration module that provides capability to assess the influence of various factors upon the behavior of an engine during the real-time simulation [9].

This feature provides capability to develop a virtual lab on the basis of ASTRA and to solve such problems as: - Investigation of dependency of engine parameters upon the ambient conditions, mode of operation and flight condition;

- Investigation of transient modes of engine operation at various conditions and for various engine control program settings;

- Optimization of the control program for the processes of engine acceleration and deceleration;

- Visual representation of joint operation of the engine elements.
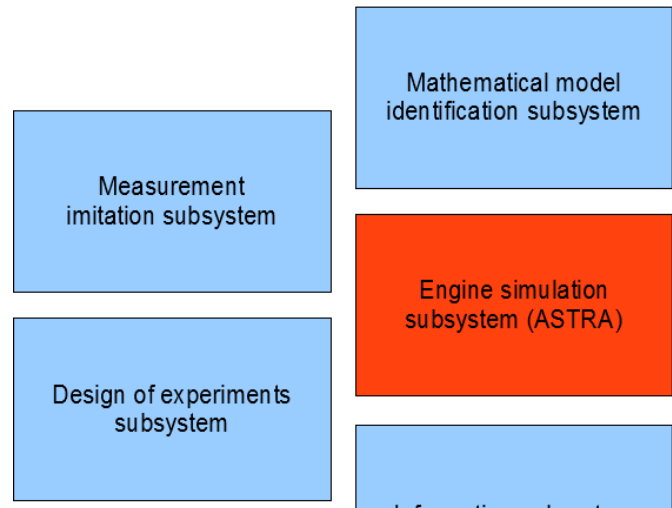

Documentation subsystem
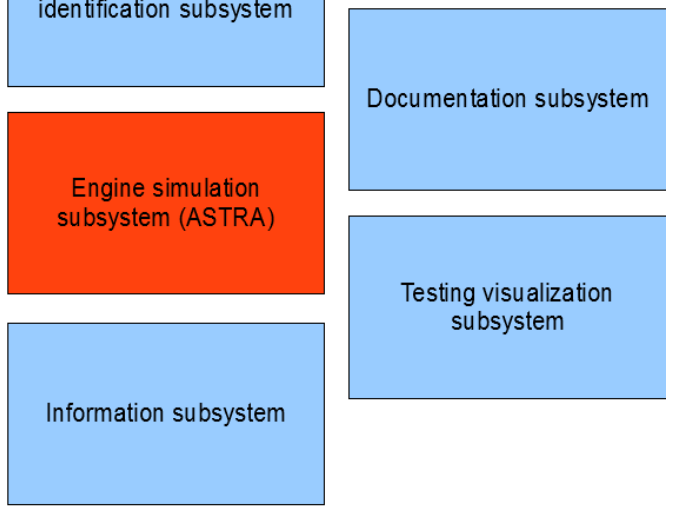

Figure 1. Virtual testing lab structure.

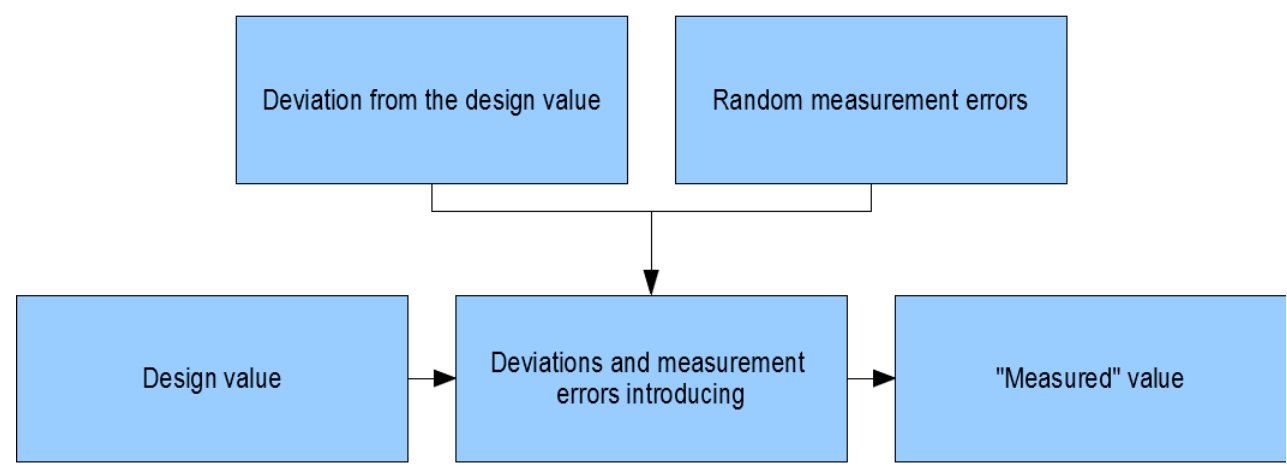

Figure 2. Scheme of deviations and measurement errors simulation.

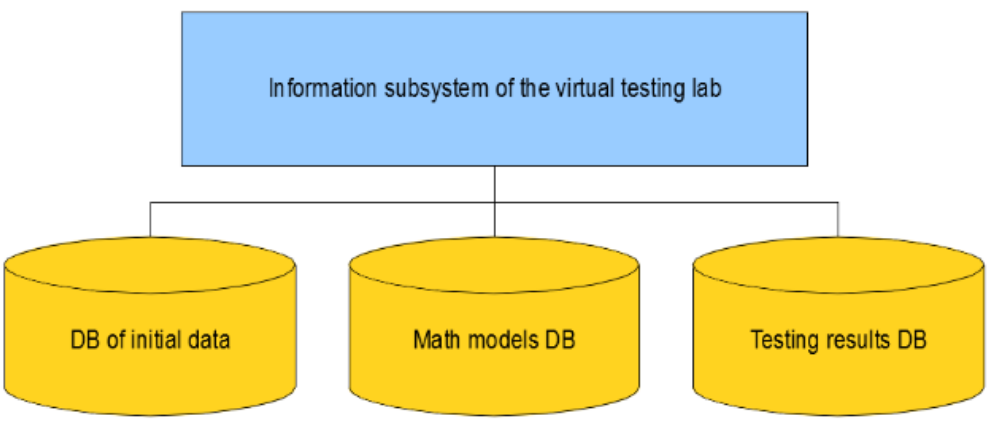

Figure 3. Scheme of the information subsystem 
The power balance of turbine and compressor is not satisfied during the transients and it is the feature of this modes of operation. The difference between the turbine and compressor power determines the kinetic energy increment of the rotating mass of the rotor:

$$
N_{\mathrm{T}} \cdot \eta_{m}-N_{\mathrm{K}}=\frac{d E}{d t}, \text { where }
$$

$E=I \cdot \omega^{2} / 2-$ kinetic energy of the rotating mass of the rotor; $I$ - rotor polar moment of inertia; $\omega=\pi n / 30$ angular velocity.

Values of power produced by the turbine and consumed by the compressor at the given value of fuel flow-rate during the calculations of transient modes of operation are evaluated on the basis of combination of working process parameters and angular velocity of the rotor at the given moment of time.

These values, in turn, determine the value of angular acceleration. The angular velocity of rotor is evaluated by means of numerical integration of rotor motion equation. Other parameters are evaluated using the quasi-stationary concept (using the same equations as for the stationary modes of operation). Thus, the transient thermogasdynamic model includes the same modules as the steady-state thermogasdynamic model except for the modified module of the engine transmission.
This transient thermogasdynamic model may be used to imitate the engine behavior during the testing and thus provide the information required for the planning of physical experimental investigations.

This model was implemented as a virtual testing lab of low-sized gas turbine engine "ASTRA $5.0 \quad \mathrm{~T}$ microGTU" using the object-oriented language (Java). Fig. 4 shows the interface of this virtual lab, running under various operating systems. The left panel may be used to change the values of external factors (airspeed, altitude, ambient temperature and pressure) and the parameters defining the mode of operation (angular velocity and the cross-section area of the nozzle exit section).

The middle panel provides the graphical representation of the main elements of the engine and its characteristic sections. The colour corresponds to the stagnation temperature along the flow-path. The diagrams below it represent the values stagnation temperature and pressure along the axis of engine.

The right panel shows the digital and pointer indicators of the main parameters of the engine.

Graphical representation of compressor characteristic with calculated operating points during the transients is located in the right-bottom corner of the window (Fig. 5).

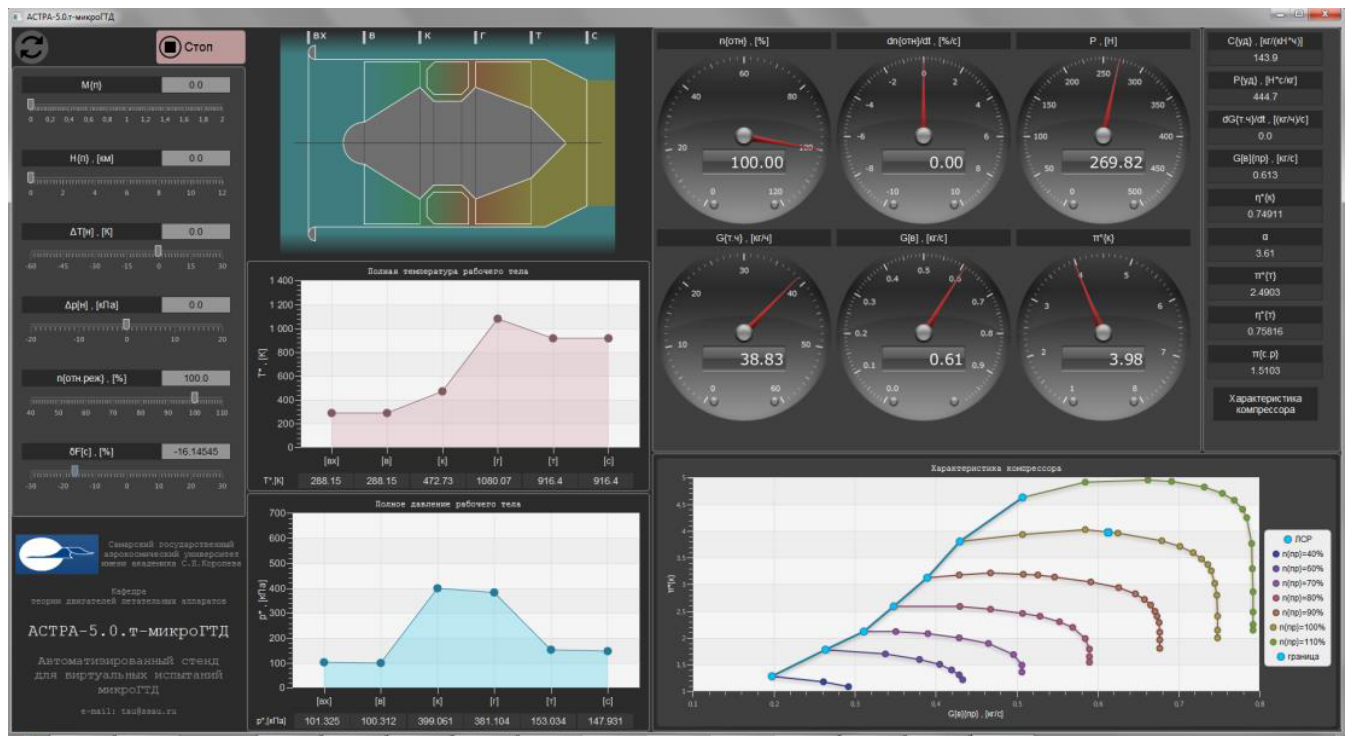

Figure 4. Virtual testing lab of the ASTRA system.

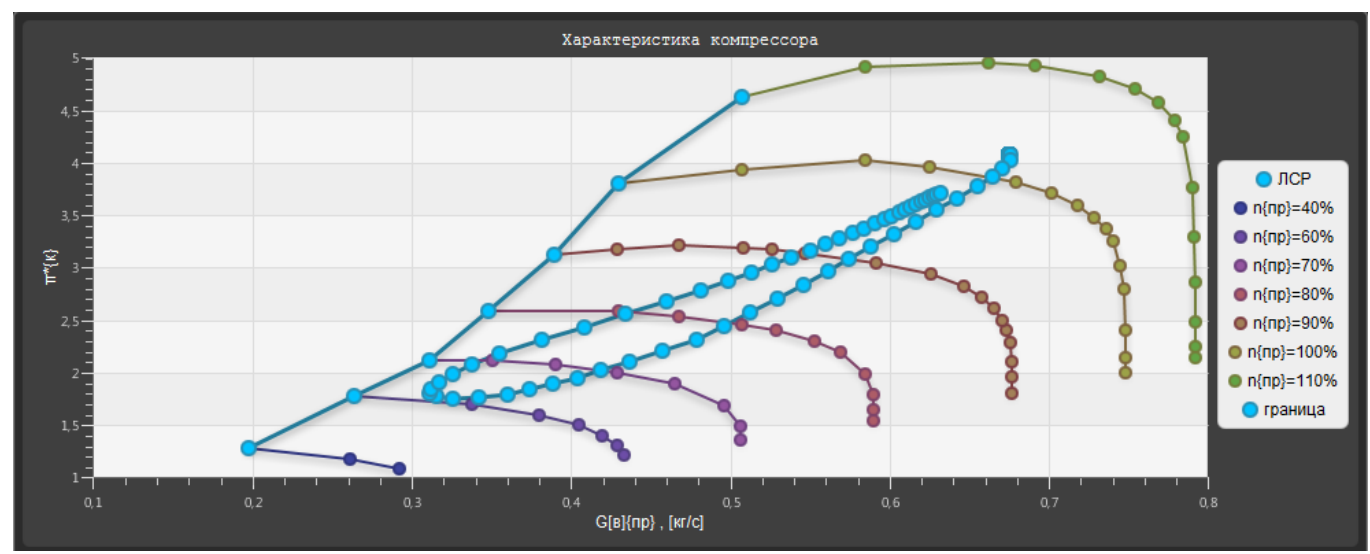

Figure 5. Graphical representation of compressor characteristic with calculated operating points during the transients. 


\section{Conclusion}

A concept for creating the virtual lab using the real-time simulation modelling of the gas turbine engines is proposed.

Virtual testing lab intended for experimental investigation of a virtual prototype of an engine that is implemented using a simulator instead of an engine itself was developed at the Department of Aircraft Engines Theory of Samara National Research University using ASTRA - the computer-aided system of thermogasdynamic calculation and analysis.

Virtual experimental investigations may be used for mathematical model identification and providing the initial data for designing physical experiments decreasing time costs and expenses.

The work was financially supported by the Ministry of education and science of Russia in the framework of basic part of government assignment.

\section{References}

1. Popov, G.M., Goryachkin E. S., Baturin O.V. and Kolmakova, D.A., 2014, "Development of recommendations on building of the lightweight calculation mathematical models of the axial turbines of gas turbine engines", International Journal of Engineering and Technology, 6(5), pp. 2236-2243.

2. Kolmakova, D.A., Baturin, O.V. and Popov, G.M., 2014, "Knowledge lack impact assessment of the source date on numerical simulation results of operational process in axial flow turbine blade row", ARPN Journal of Engineering and Applied Sciences, 9(12), 2014, pp. 2880-2889.
3. Kuz'michev, V.S., Tkachenko, A.Y., Krupenich, I.N., Rybakov, V.N. "Composing a virtual model of gas turbine engine working process using the CAE system "ASTRA", Research Journal of Applied Sciences, 9(10), 2014, pp. 635-643.

4. Tkachenko, A.Yu., Kuzmichev, V.S., Kulagin, V.V., Krupenich, I.N., Rybakov, V.N. "Computer-aided system of thermogasdynamic calculations and analysis (ASTRA 4) of gas turbine engines and power plants", Problems and development prospects of propulsion engineering: materials of the international scientific and technical conference held on the 28-30th of June, 2011, Samara: SSAU, 2011. In 2 parts. Part 2. - pp. 80-82. (In Russ.).

5. Tkachenko, A.Yu., Krupenich, I.N. "Development of a virtual prototype of gas turbine engine at the stage of conceptual thermogasdynamic designusing the CAE-system «ASTRA»", Vestnik SSAU, 2012, №3(34), Part 2, pp. 333-342. (In Russ.).

6. Rybakov, V.N., Kuzmichev, V.S., Tkachenko, A.Yu. "Concept of construction of virtual lab for gas turbine engine testing", Vestnik SSAU, 2011, №3(27), Part 3, pp. 326-330. (In Russ.).

7. Rybakov, V.N., Kuzmichev, V.S., Kulagin, V.V., Krupenich, I.N., Fedorov, D.V. "Dataware of virtual lab for gas turbine engine testing", Vestnik SSAU, 2011, №3(27), Part 3, pp. 320-325. (In Russ.).

8. Kuzmichev, V.S., Rybakov, V.N. "Principles and methods of the virtual laboratory tests of gas turbine engines”, Vestnik UGATU, 2012, Vol. 16, №2(47), pp. 199-202. (In Russ.).

9. Kuz'michev, V.S., Rybakov, V.N., Tkachenko, A.Y., Krupenich, I.N. "Optimization of working process parameters of gas turbine engines line on the basis of unified engine core", ARPN Journal of Engineering and Applied Sciences, 9 (10), 2014, pp. 1873-1878. 